\title{
The Culture of Sexist Language among Male University Students in Ghana
}

\author{
Kari Dako, ${ }^{1, *}$ \\ ${ }^{1}$ Department of English, University of Ghana, Ghana \\ *Correspondence: P.O.Box LG 129, LEGON-ACCRA, Ghana. E-mail: karidako@gmail.com
}

Received: October 21, 2013 Accepted: October 31, $2013 \quad$ Online Published: November 22, 2013

doi:10.5430/wjel.v3n4p19 URL: http://dx.doi.org/10.5430/wjel.v3n4p19

\begin{abstract}
This article is about women as conceptualised by male university students and how their attitude towards women is revealed in the vocabulary they use to refer to females and the sexual act. It is based on a letter that appeared in a Ghanaian newspaper some years ago. For the purpose of this article, the text has had all names and references to places and institutions altered. The letter deals with a young woman who, some years ago, hit the headlines by accusing a prominent politician of rape. As the press dived into the issue, the credibility of the woman was questioned. In this text she is not a victim, she is among other designations a "devil of a girl” and a "Jezebel”. Her nickname is “Ashokabula" - a compound of the pidgin 3.p.s. pronoun “a” (wa), the English verb "shock” and the Hausa noun "bula” (penis). The vocabulary referring to the woman we are dealing with reflects what Fairclough (1993) calls "overwording”. The article poses the questions: What should appear in print and what should not appear in print? Should the language of the locker room appear in print?
\end{abstract}

Keywords: Ghanaian English; university slang; male attitudes; verbal defilement

\section{Introduction}

This article is about a letter written in English that appeared in a Ghanaian newspaper some years ago. English is the official language of Ghana, and therefore also the language of the printed press. Yet Ghana is a highly multilingual country with “approximately 50 non-mutually intelligible languages” (Anyidoho and Dakubu Kropp 2008: 142) and these languages reflect ethnic groups, each with a distinct language and its dialects, each with its distinct culture. Ghana also has a multitude of Christian denominations and sects but also several Muslim factions as well as thousands of religious groupings connected with traditional shrines. For a country of such heterogeneity to function with some homogeneity and find some cohesive elements to rally around, there is the cognition that some topics are avoided in public discourse or are discussed with utmost circumspection. However, somehow this moral sensibility does not always stretch to encompass women.

Some years ago a young woman went to press in Ghana and claimed that a prominent official had attempted to rape her. The same was under political pressure at the time, as it appeared he had spoken publicly against the Head of State on some issue. The accusation of rape was therefore by many interpreted as a means to malign the official and to destroy his reputation.

The press dived into the matter, and the credibility of the young woman was questioned. The publicly owned press tended to present her as a victim of sexual aggression; the private press vilified her.

This paper deals indirectly with this scandal, in that it uses a letter sent to the editor of a reputable privately owned paper, as its data. The letter (hereafter referred to as "the text”) was written by a male student of one of Ghana's universities. In the letter he describes how he came to know this woman who claimed she had nearly been raped. Apart from the revelation of the behavioural mode of an obviously very disturbed woman, the text is of interest in that it exposes the language of university subcultures and through that, male students' attitudes to women. In addition it exposes how insensitive the press in Ghana can be when it comes to dealing with issues pertaining to gender. We shall see that the text, of about 1900 words, has a vast vocabulary pertaining to women, a lot of which is extremely offensive sexist language. Merely allowing this text to appear in print might legally constitute slander. Likewise, it might be 
considered unethical to unearth this old scandal after so many years, but the text did appear unedited at the height of the furore in a reputable Ghanaian newspaper. Consequently we have decided to use this text once more albeit with personal names and place names changed.

The full text has been appended, and as can be seen it should have been edited before appearing in print, but it was not. In addition, the writer opens with,

\section{This is more or less a personal letter but I wouldn't mind if you extract some points from it and publish} it for public consumption...

It is clear the writer did not intend to have his letter published as he had written it. One can then wonder what caused the editor to allow it to appear in print. The writer signs the letter with full name and intimates that he is a $3^{\text {rd }}$ year university student (at that time a final year student). He would therefore belong to what Sey (1973) classifies as Stage III in the linguistic continuum of English in Ghana.

This (Stage Three) corresponds to the university level of education. The standard of English is as high as can normally be expected in a bilingual living in a predominantly L1 environment. In several 'registers' his command of English is almost native. Peculiarities at this stage are largely semantic in nature. (16)

It will be seen from the following, that the linguistic reality of English competence in Ghana has changed a great deal since Sey did his research and published his findings.

The text deals with the degeneracy of philandering university students. It is a real narrative in a homodiegetic mode. The narration relates a supposedly true sequence of events anchored by references to definite characters in time and place. The topic is a young woman, and the text gives an account of her alleged escapades. The writer sets out to inform his readership about how he got to know the person, and how his university-mates related to her and therefore perceived her during a period prior to her name being displayed in the headlines and her gaining national notoriety. We therefore expect a detached account of human acquaintanceship. But we get instead a slangy, vulgar narrative quite inappropriate to the readership the writer claims to address. (Note 1)

The text is therefore of interest beyond the lexicology of university slang, because it also reveals how inadequate the English of the average Ghanaian university student is, and how inapt in or indifferent to proof-reading to press is - but that will concern us less here. Where university slang is used, the meaning has been footnoted.

It will be shown that we can no longer take for granted that our students leave university with the requisite versatility in English which should enable them to apply for, obtain and function in job situations that require "graduate" skills. It will further be demonstrated that it is especially in the choice of register, in idiomatic usage and in vocabulary that the university student today exhibits lack of linguistic ability and sensibility.

Bell (2001:141) posits as part of his theoretical framework of Audience Design, that "style is what an individual does with a language in relation to other people”. In other words, our letter writer had a readership in mind. Bell further posits (ibid) "style derives its meaning from the association of linguistic features with particular social groups". As this paper shows: the linguistic features highlighted belong to a distinct social group: male university students.

There are two other issues, although tangential to this text that might be relevant here. The major ethnic group in Ghana, the Akan, is matrilineal. Women are thus traditionally in a strong position, socially, financially and politically. The Akan attitude to women has influenced neighbouring groups that are patrilineal. It can be argued that because women stand so strong, and men are not even in control of their own offspring, for instance, there might be an underlying misogynous attitude in both traditional and contemporary Akan society that in a way exposes the emasculation of the male in this matrilineal society of powerful women.

In support of this, Sutherland-Addy (2006:255) gives the example of a well-known maxim in contemporary Ghana that is echoed in popular culture: Fear woman! This, Sutherland-Addy says, is a fragment of the axiom "Fear woman and live long”. The fragment is often seen painted on trotros(Note 2) and used as a name for shops and eating-places. Sutherland-Addy argues that whereas Akan culture savours circumlocutory innuendos and equivocations and the avoidance of expressing things directly; in contemporary society women are often openly denigrated. She transcribes a popular high-life(Note 3) text to support this claim:

It is not all woman that one can marry

Afrakuma likes /To roam about too much

She has no time to light up the hearth 
Dog woman / When I teach her anything

she cannot grasp it / She sits there stupidly

Sheep / Afrakuma

Thievery /Cat-woman

Hot-headedness and stubbornness

Etc.

Afrakuma is also a Goat-woman and a Chicken-woman and a Pig-woman - and the song ends with the admonition 'Get a grip of yourself so that you can be called Human-woman'.

We shall see that this high-life text resonates in our text; for our text has no delicate innuendos, nor any subtle allusions. Essie is called names and there is no ambiguity about them.

Van Dijk (1993:262) argues that derogatory vocabulary and impoliteness is the result of the "activation” of "underlying bias” in social attitudes, and in van Dijk (2007:113) he posits that social attitudes are part of what he calls "social collectivities” that encompass "knowledge, attitudes, ideologies, norms and values” of a society. This paper concerns itself primarily with this "group knowledge” (114 ibid) and how attitudes to groups within society are represented in that it is based on a text that reveals young males' perception of a young woman and their attitudes towards her. Van Dijk is of the opinion that group knowledge is "biased and ideological” (114 ibid). Meyer's (2007:15) point of view is: "...that all discourses are historical and can therefore only be understood with reference to the context." - and Fairclough (1994) uses the term “overwording” (as used by Fowler et al. 1979:210):

It is useful to compare the wording of particular domains from particular perspectives in terms of relative density, that is, in terms of the number of different wordings (including lexical items) that are generated, many of which will be near synonyms. ... Overwording is a sign of 'intense preoccupation' (emphasis mine) pointing to 'peculiarities in the ideology' of the group responsible for it. (193)

We are thus focussing on the historical environment in which the text is set: a political scandal, and the vocabulary associated with the domain of the text: what we will refer to as the locker-room. No doubt young men are preoccupied with the opposite sex and have developed an extensive vocabulary to express that obsession; their attitudes, however, reflect their limited environment's social cognition of women. In this text we are, therefore, dealing with a type of vocabulary hardly found in a dictionary. Montgomery (1986:177) describes such lexical items as having...

...resonances of certain all-male subcultures: the adolescent male peer-group, the locker-room and the building-site subcultures. As they are more likely to be used by men...

Usually the language of the locker-room does not escape that confined space - which is the arena where the young male can blurt out any taboo expression and give voice to his societal prejudices. But the door was left ajar in this case, and the aspersions landed on the pages of a widely circulated newspaper.

While the press in Ghana approached the "historical context”, i.e. the news story this article is based on, from opposing angles, either as: Essie is a victim of sexual aggression from an old man; she has been raped - or as: Essie is promiscuous; she has let herself be used for political expediency - our text is set in a different domain: the university locker room. And the preoccupation of this text is not the scandal itself but the woman at the centre of the scandal.

\section{Analysis of the Text}

We will regard the text used for this paper as the verbal defilement of a young woman by a male university student.

- She is cast in the most seditious roles of a female: she is projected as sexually aberrant (called Ashokabula(Note 4)),

- It is hinted that she might be mentally disturbed (... he thought the girl was experiencing some form of hallucinations).

- It is alleged she tells lies: ‘. . . the girl was not consistent in most of her information'.

- It is even suggested there might something supernatural about her or that she might be mentally ill: '- because I had a premonition that she may be either a witch or a mental patient'.

- According to the text she defends herself by accusing those around her of attempting to rape her, and the assumption projected is that all allegations of rape are without truth.

'So you see here that any time this “Jezebel” wants a favour from you and she doesn't get it, the weapon she uses is 
“you've raped her”.'

The effaced subtext, on the other hand, indicates that she has indeed been the victim of repeated sexual abuse.

- She is the victim of vicious gossip, hear-say and conjectures:

“ ... a friend of mine ... had blown(Note 5) me about a girl bearing that name but was popularly referred to as ASHOKABULA”.

“... He reported later to his paddies(Note 6) that the girl has shocked his supposedly big bula(Note 7) “.

"Words started spreading about this girl...”.

“...information (filla) which filtered through campus was that the people were taking time off their learning periods to go and 'link-up-with-her' (Note 8)”.

“They came back to report that the girl was such a flirt that they were even afraid for 'hearing' (campus word for sex) her even though they used condoms”.

How is a woman defiled through language? The overwording in the text as well as the device of repetition demonstrates how it is done.

\section{Vocabulary}

In this paper four vocabulary categories will be looked at:

- terms used to describe the female

- terms used to describe the sexual act

- terms used to describe the male organ

- $\quad$ terms used to describe the male

Through a breakdown of vocabulary items pertaining to the female used in the text, we note that nowhere is the neutral term "female” used, and “woman” is used only once:

“... his genital organ was so big that hardly does a woman consent to his sexual advances”.

Her name, Essie, is used only three times:

“...the next issue which features an interview with Essie Mensah on the Dadson case”.

“... I got to know of this “devil of a girl” called Essie Mensah ... in 1992 “.

“ However, an encounter with this 'Essie chick' led to the realisation..."

In the universities of Ghana, female students are referred to as "ladies" and the female students refer to each other as such. The term "girl” is used, but mostly to create distance and as an avoidance of using a name. "I know that girl ..." - "Those girls in Addo Owusu Hall ...”. "Girl” can also be a carry-over from the colonial era, when adult males were named "boys” and adult women might be “girls” (Note 9). The expression "small girl” is also frequently used in Ghana - it is a disparaging designation and signals "of no significance”. "Girl” also connotes someone young, not fully adult, a plaything that need not be taken seriously - thus "girlfriend" is a lover, and she might not be considered a future wife. The writer of our text uses the term "girl" over 30 times and the use of this noun creates distance between the narrator and the person spoken about, whereas, as we shall see later: all references to males connote closeness and friendship.

1. “... I got to know of this 'devil of a girl' ... in 1992.”

2. "Prior to that, a friend of mine, through our normal conversation had 'blown' me about a girl bearing that name...."

3. "He reported later to his paddies that the girl has shocked his supposedly big bula."

4. "Words started spreading about this girl who was after admission(Note 10)..."

5. "They came back to report that the girl was such a flirt...”

6. “... a lot of things happened in the life of this Ashokabula girl.”

7. “...when he got to know about the girl's mode of life ...”.

8. “(I must admit that even if Lucifer comes into contact with this girl, he will be moved to advice (sic) her to go for spiritual deliverance).” 
9. "This girl nearly caused trouble for this aspiring T.A.” (Note 11)

10. "The T.A. then decided to accompany her to the line on which the room was to find out for himself but the girl refused."

11. "Later on he thought the girl was experiencing some form of hallucinations."

12. "The girl pleaded to sleep with him but this guy was expecting his girlfriend the next morning so he refused."

13. "The girl disappeared so early in the morning that my friend began to entertain some fears..."

14. "...my friend began to entertain some fears as to the identity of the girl."

15. "Later in the day, this girl resurfaced and told how she had been 'swerved'(Note 12)..."

16. "The T.A. confessed... he can't entertain the girl any longer so she should willingly leave the hall."

17. 17. "Later on this girl returned and labelled the T.A . as a rapist, spreading the wrong filla(Note 13) that the T.A. had raped her."

18. "This girl was still hovering around with no particular place to sleep."

19. "When we saw the girl, we talked for some short period and wished her good luck in her admission endeavours."

20. "My roommate then told me how this girl gate crashed at PSXY, how she was sacked after the detection and how she later was sacked at St. Barbara ..."

21. "It was here that he told me about the girl's blood relation with Tom Mensah, then boss at Spiderweb."

22. "This girl told us that, and I quote, 'Now that I've been given admission dee(Note 14) I am not sure I will come to Kat for some personal reasons'.”

23. "On the day of the matriculation, this girl was there live and coloured(Note 15) [and] splendidly dressed."

24. "...that filla indicates that they are harassing the girl and even raped her when the girl was on campus."

25. "This SM(Note 16) man then narrated to us how he came into contact with the girl."

26. "He said the girl approached her (sic) one day and told him her roommate had gone to lectures and as such...”

27. "It took three days for the girl to come back again with more items, giving the same excuse."

28. “...the girl told him that her roommates are now four and as such, she can't cope with the situation so she intends to change her hall ...”

29. "However, the girl was not consistent in most of her information..."

30. “... that was why the girl was spreading such a false filla."

31. "One interesting thing is that I found this girl almost always walking alone on a road ..."

32. “...my roommate and I met this girl coming out of our main Library with a pen in hand."

33. “...my roommate began to entertain some surprise because as far as he was aware this girl was registering among the Arts Students when she was sacked from PSXY."

34. "Since then, I never saw this girl and later, we learnt she couldn't even enter the $6^{\text {th }}$ form after all."

As can be noted in these examples - the writer is watching "the girl" and listening to the gossip about her, and so he always finds something unusual in her behaviour to comment on.

The young woman is five times referred to as "chick", a degrading term which no woman in Ghana would allow anyone to use in connection with herself:

1. "However, an encounter with this 'Essie chick' led to the realisation that ..."

2. "I was walking with this guy when we suddenly bumped into this chick."

3. "This chick was still around."

4. "(By then the chick had vanished from campus)." 
5. "I quite remember we saw this chick only twice at [the] Lecture Area."

This woman is also dangerous, she is a devil and possibly a witch:

“...I got to know about this 'devil of a girl' called ..."

"I began to monitor her movements for future reference because I had a premonition that she may either be a witch or a ..."

She is a temptress - a danger to the young men who are obviously intrigued by her and attracted to her:

"So you see here that any time this 'Jezebel' wants a favour from you and she doesn't get it, the weapon she uses is 'you've raped her'."

"That was my first time with this temptress."

"They came back to report that the girl was such a flirt..."

She might be sick - and a mental patient ... (Note 17)

"I had a premonition that she may...be ... a mental patient."

"... he thought the girl was experiencing some form of hallucinations."

There might be something insubstantial about her. In a highly superstitious society, such as Ghana, the suggestion of any connection with the occult or the paranormal is extremely dangerous; alleged witches may be banned from society or even killed.

“... I had a premonition that she may either be a witch or ...”

"...my friend began to entertain some fears as to the identity of the girl. (A ghost or a normal human being?)"

And we are told that she has used the allegation of rape repeatedly - but we also note the frequent occurrence of the term "rape" in the text:

1. “..., Ashokabula told him some two guys had wanted to rape her in her room..."

2. " "... I learnt she was accusing a Registrar and lecturer that they had raped her)."

3. “... this girl returned and labelled the T.A. as a rapist, ...”

4. “... spreading the wrong filla(Note 18) that the T.A. had raped her."

5. " So you see here that any time this "Jezebel” wants a favour from you and she doesn't get it, the weapon she uses is 'you've raped her'."

6. "... the filla indicates that they were harassing the girl and even raped her..."

She is given the profane nickname Ashokabula, and we are given a detailed etymological breakdown as to meaning and significance of this name. Essie is therefore portrayed as promiscuous and morally decadent:

1. "Prior to that, a friend of mine, through our normal conversation had 'blown' me about a girl bearing the name but was popularly known as ASHOKABULA. According to the friend, the name Ashokabula was coined from the phrase 'Wa shock ne bula' which literally means (even though profaneous (sic)) 'She has shocked his penis/prick/bula'. The genesis of this name was that there was a guy in $\mathrm{XX}$ whose genital organ was so big that hardly does a woman consent to his sexual advances for the second time after an ongoing first traumatic sex session with him.'

2. "Since then, most guys went and tested for themselves and soon started calling her Ashokabula because of the ease with which she 'swallows their pricks'."

3. "However, during the vacation, a lot of things happened in the life of this Ashokabula girl."

4. "Asked what was the problem, Ashokabula told him some two guys had wanted to rape her in her room."

In Ghana, as in so many other places in the world, a woman is not supposed to exhibit any overt sexual desires, modest or excessive, whoever be the judge. So the male reaction to what he perceives as unacceptable sexual behaviour is ill defined. Whereas we know that in some societies a woman can be killed for the slightest slur on her behaviour vis-à-vis the opposite sex, in Ghana the attack is on her reputation, which is then tainted through gossip and naming. That the term, Ashokabula, was allowed to escape from the locker-room and find refuge on the printed page is scandalous. And yet the author blames the woman.

On the other hand, although we are told that many males apparently had had carnal knowledge of her, there is no 
negative reaction in the text to male behaviour when it comes to sex.

Males in the text are referred to as: "friend":

1. "Prior to that, a friend of mine, ... had 'blown' me about a girl ..."

2. "The friend attended PSXY..."

3. "According to the friend,..."

4. "I had a final year Science student friend..."

5. "What she told this T.A. friend of mine..."

6. "This girl disappeared so early in the morning that my friend..."

7. “...we bumped into Senior Player man in one of my friends at Presby's room..."

Guy is also a positive term, and hints at a popular young man. It is used seven times in the text:

1. "...there was a guy in PSXY..."

2. "Since then most guys went and tested for themselves..."

3. "I was walking with this guy..."

4. "Ashokabula told him some two guys wanted to rape her..."

5. “... but this guy was expecting his girlfriend...”

6. "The guy was popularly called Senior Player..."

7. '.. this course mate was teasing the guy, ...'

Roommate is also used seven times:

1. "Fortunately my new roommate, John Adjei..."

2. "My roommate then told me how this girl gate crashed..."

3. "My roommate and I met her ..."

4. “... where my roommate can contact her...”

5. “... my roommate was there on three occasions..."

6. “...my roommate and I met this girl...”

7. “... my roommate began to entertain some surprise ...”

Senior Player or SM is a flattering term used to refer to an older popular student. It is used four times:

1. "This guy was popularly called Senior Player (he was my draught-play mate)."

2. “...we bumped into this Senior Player man..."

3. “... this course mate was teasing the guy (Senior Player or SM for short)..."

4. "This SM man then narrated to us how he came into contact with the girl."

Course mate and paddies are other terms used to refer to male students and friends.

Some of these designations are slang expressions or belong to the university jargon, but none are negative. The writer has obviously an adequate vocabulary with which to narrate his story.

The sexual act, obviously a popular theme for deliberation, has also several synonyms and is referred to as:

“ashokabula” (Wa shock ne bula) (She has shocked his penis/prick/bula)

"first traumatic sex session with him"

“... every bolt has a spanner"

"... guys went and tested for themselves"

“...swallows their pricks ...”

“... link up with her ...”

“...hearing' (campus word for sex) ...”

“... rape” 
None of these terms can be termed neutral - there is no mention of "intercourse" or "intimacy" or even "love" - it is as if the sexual act itself connotes illicit behaviour and can only be described through euphemisms.

The male organ is also “overworded”, if we can make a verb from Faiclough's term, and is referred to as:

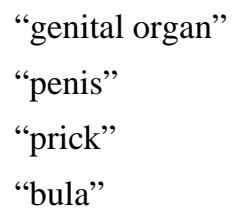

What does this say about the young Ghanaian male? In this text he is projected as a nice guy; the male students are all friendly towards each other. But the only woman mentioned is described absolutely negatively. The subtext is about the sexual relations on a university campus. The topic is sex, which appears to be a major preoccupation among the male students, and as a result it appears they also feel free to vilify a woman publicly. This is a new phenomenon in Ghana. Decorum in speech and in writing has always been valued in Ghanaian culture, and this cuts across ethnic boundaries. It is shocking that a young man feels entitled to insult a woman with the metaphor: Ashokabula. How can a woman with this nickname exonerate herself?

\section{The Writer's English}

But the text also exposes the inadequacy in the language of the writer, as observed in the following structural and idiomatic oddities found in the text. (Acceptable alternatives are suggested in brackets).

- " "- take time off their learning periods - “ (take time off from reading / studying)

- "- he was by name N.N. -“ (he was called N.N. / his name was N.N.)

- " “- a Kumasi-based Ghanaian - " ( a chap from Kumasi / 'Ghanaian' is redundant)

- "- he was moved emotionally to help- “ ('emotionally' is redundant)

- " “- her rent was so biting that if she doesn't take time, she will be forced to..." (ST is inconsistent; slang 'rent was biting' i.e. 'high / she could not afford it; for "if she doesn't take time" read: 'if she does not take care').

- “- it was about 2 a.m. in the dawn." ('2 am' / 'two in the morning' - - 'dawn' collocates with 'at': at dawn).

- " "- the complexities arising from her screaming at the dawn-" (the idiom is 'at dawn' and not variable in this context).

- “- We ... congratulated her for her admission...” ('we congratulated her on her admission..')

- "- All these while -" (all this while / all this time)

- " “- she was having her items in a boy's room.” ('she had / kept her things in a boy's room')

- " "- He said the girl approached her one day and told him." (... he said the girl approached him ....and told him.)

- "- the girl was not consistent I most of her information so he decided to do away with her." （wrong choice of idiom: 'do away with her' means 'finish her off' / 'kill her')

- " “-In a chat she said.” (wrong collocation, read: 'during a chat' / in conversation')

- “- did some work in Mathematics because it was giving her tough times.” (wrong idiom: 'it was giving her a tough time')

- “- began to entertain some surprise-“ ('entertain some doubt')

- “- so herein comes my agitations-“ ('so this is my problem')

- “ - I need to see you in person and talk over bottles.” (ambiguous: / 'discuss bottles'? - or 'talk over a couple of bottles'?)

- “- have my condolance [sic] for your pop’s death-“ ('have my condolence on your father’s death' - 'pop’ is slangy and therefore wrong choice of register.)

- “ - Since then, I never saw this girl and later, we learnt...” ('Since then I have never seen this girl, and later we have learnt...') 


\section{Concluding Remarks}

Our letter writer has communicated well - he has fanned a newsworthy story even though through 'broken English'(Note 19). The newspaper that received the letter did not bother to do any editing - the story was obviously so in line with the current political discourse that the mode of expression did not matter to the editor.

One can speculate about public reaction if this text had been rendered in a Ghanaian language. There would most likely have been public outcry. We note that not one of the offensive vocabulary items comes from a Ghanaian language(Note 20). From work done on the English of male university students in Ghana (Nettey 2001; Dako 2012), it appears that English and Pidgin are the languages that students feel free to use when sensitive issues are discussed, because they can then perceive themselves as functioning beyond the realm of traditional decorum. When, on the other hand, English is the mode, the perception appears to be that "anything goes".

- And Essie Mensah’s name has been sullied forever.

\section{References}

Anyidoho, Akosua \& Dakubu Kropp, M. E. (2008). Language, nationalism and national identity in Ghana. In Language and National Identity in Africa, Andrew Simpson (ed.), 141-157. Oxford: Oxford University Press.

Bell, Allan. (2001). Back in style: reworking audience design. In Penelope Eckert and John R. Rickford (eds) Style and Sociolinguistic Variation. Cambridge: CUP, 139-169.

Dako, Kari. (2002a). Pidgin as a gender specific language in Ghana. Ghana Journal of English Studies, 1, 73-82.

Dako, Kari. (2002b). Student Pidgin (SP) - the language of the educated male elite. IAS Research Review, 18(2), 53-62.

Dako, Kari. (2012). Pidgin: a masculine code encroached on by young women. In Jan Sutherland (ed) Language and Gender in Sub-Saharan Africa. Amsterdam: John Benjamin. (in print)

Fairclough, Norman. (1993). Critical Discourse Analysis: the Critical Study of Language. London: Longman.

Fowler, R., Hodge, B., Kress, G., \& Trew, T. (1979). Language and Control. Routledge: London.

Meyer, Michael. (2007). Between theory, method and politics: positioning of the approaches to CDA. In ed. Ruth Wodak and Michael Meyer, Methods of Critical Discourse Analysis, London: Sage Publications.

Montgomery, M. (1986). An Introduction to Language and Society. Routledge: London. http://dx.doi.org/10.4324/9780203312032

Nettey, Reuel Christopher. (2001). Linguistic Interaction among Male Students at the University of Ghana-Legon. A Micro Study. Unpublished Long Essay, Department of English, University of Ghana.

Sey, K.A. (1973). Ghanaian English: An Exploratory Survey. London: Macmillan.

Sutherland-Addy, Esi. (2006). “"Fear Woman”: the image of women in Contemporary Ghanaian Popular Performance Arts’. In ed. C. Oppong, M.Y.P.A. Oppong and I.Odotei: Sex and Gender in an Era of AIDS. Accra: Sub-Saharan Publishers.

Van Dijk, T.A. (1993). Principles of critical discourse analysis. Discourse and Society, 4, 249-283. http://dx.doi.org/10.1177/0957926593004002006

Van Dijk, T.A. (2007). Multidisciplinary CDA: a plea for diversity. In ed. Ruth Wodak and Michael Meyer, Methods of Critical Discourse Analysis, London: Sage Publications. 
Text

This is more or less a personal letter but I wouldn't mind if you extract some points from it and publish it for public consumption, as has always been your objective. My schedule, I must admit, will not allow me to type this piece before posting which could have satisfied the required criteria for publishing it, but I hope you will treat it with all the urgency it requires before Monday when you come out with the next issue which features an interview with Essie Mensah on the Dadson case.

I'm a $3^{\text {rd }}$ year student at X University currently on vacation attached to a private company. To begin with, I got to know of this "devil of a girl" called Essie Mensah when I was in the $1^{\text {st }}$ year in 1992. Prior to that, a friend of mine, through our normal conversation had "blown" me about a girl bearing that name but was popularly referred to as ASHOKABULA. The friend attended PSXY, Kwamekrom and got to hear and know if her whilst he was in secondary school. According to the friend, the name Ashokabula was coined from the phrase "Wa shock ne bula" which literally means (even though profaneous (sic) "She has shocked his penis/prick/bula". The genesis of this name was that there was a guy in PSXY whose genital organ was so big that hardly does a woman consent to his sexual advances for the second time after an ongoing first traumatic sex session with him.

However, an encounter with this "Essie chick" led to the realisation that "every bolt has its spanner". He reported later to his paddies that the girl has shocked his supposedly big bula. Since then, most guys went and tested for themselves and soon started calling her Ashokabula because if the ease with which she "swallows their pricks". So the name came to stay.

So it came to pass that when it was getting to the end of the $1^{\text {st }}$ year, $2^{\text {nd }}$ semester, I was walking with this guy when we suddenly bumped into this chick. Since then, I began to monitor her movements for future reference because I had a premonition that she may either be a witch or a mental patient.

Words started spreading about this girl who was after admission and had consequently hired a room at Suburba, a township near the university.

We were by then approaching our exams week but information (filla) which filtered through the campus was that people off their learning periods to go and "link-up-with-her". They came back to report that the girl was such a flirt that they were even afraid for "hearing" (campus word for sex) her even though they used condoms.

After the exams, we all went home for the vacation pending our entry into the $2^{\text {nd }}$ year. However, during the vacation, a lot of things happened in the life of this Ashokabula girl. I had a final year Science student friend who comes from Suburba township who had finished his course that year. And was to be engaged as a Teaching Assistant during his National Service on campus. He was called Peter Wilson and was a Hall Executive in his final year so he was in a single room in Annex 2 of Culture Hall. Because he was to be a T.A. and moreso a local man, he was in the same room during the vacation. However, when he got to know of the girl's mode of life at the Suburba township, he was moved emotionally to help her.

(I must admit here that even if Lucifer comes into contact with this girl, he will be moved to advice (sic) her to go in for spiritual deliverance).

What she told this T.A. friend of mine was enough to move him. He, therefore, arranged for her to secure a room in Culture Main Hall for that short period. Actually, she said she was on the verge of securing admission but her rent was so biting that if she doesn't take time, she will be forced to sleep at Pele Stadium till the admission is offered her.

This girl nearly caused trouble for this aspiring T.A. when on the second night of her stay she ran from her room barefooted and climbed the $8^{\text {th }}$ floor of the Annex where the T.A. was sleeping, screaming all along. (The T.A. told me it was about 2 a.m. in the dawn). Asked what was the problem, Ashokabula told him some two guys had wanted to rape her in her room. The T.A. then decided to accompany her to the corridor on which her room was to find out for himself but the girl refused. What baffled this T.A. was that it was long vacation and no student, as far as he was concerned was on campus, except the porters. He even went on to conclude that she was having nightmares or was a sleepwalker. Later on, he thought the girl was experiencing some form of hallucinations.

The girl pleaded to sleep with him but this guy was expecting his girlfriend the next morning so he refused. He, however, secured the next-door neighbour's room for her, by scaling onto the balcony. (See the risk involved). This girl disappeared so early in the morning that my friend began to entertain some fears as to the identity of the girl. (A ghost or a normal human being?).

Later in the day, this girl resurfaced and told how she had been "swerved" by those who promised her the admission. (Later on in the semester, I learnt she was accusing a Registrar and lecturer that they had raped her). She, 
therefore, pleaded with the aspiring T.A. to help her if he can. This T.A. confessed that he doesn't have any connections whatsoever and from the complexities arising from her screaming at that dawn (It attracted the attention of the Porter and the Security man on duty) he can't entertain the girl any longer so she should willingly leave the hall.

Later on, this girl returned and labelled the T.A. as a rapist, spreading the wrong filla that the T.A. had raped her. So you see here that any time this "Jezebel" wants a favour from you and she doesn't get it, the weapon she uses is "you've raped her". After the vacation, we all came to school for the $2^{\text {nd }}$ year. This girl was still hovering around with no particular place to sleep. Fortunately, my new roommate John Adjei attended PSXY at Kwamekrom for his sixth form course. When we saw this girl, we talked for some short time and wished her good luck in her admission endeavours. (That was my first time with this temptress. My roommate then told me how this girl gate crashed at PSXY, how she was sacked after the detection and how later she was sacked at St. Barbara (as you rightly reported). It was here he told me about the girl's blood relation with Tom Mensah, then boss at Spiderweb.

We broke for the Christmas holidays and came back January $15^{\text {th }}$. This chick was still around. My roommate and I met her one day and told her we will be going to Kwamekrom on January $20^{\text {th }}$ so if she has a message for her junior brother she should bring it to us at Methodist Hall, Room ZX. This girl told us that, and I quote, "Now that I've gained admission "dee" I'm not sure I will come to Methodist for some personal reasons". Unquote. We even congratulated her for her admission. She gave us a room number where my roommate can contact her for the message, but lo and behold, my roommate was there on three occasions but was told that only boys sleep in that room. (The hall was Presby).

On the day of the matriculation this girl was there live and coloured [and] splendidly dressed. Those in Presby even said the food she brought was mega. All these (sic) while, as I gathered later, she was having her items in a boy's room. The guy was popularly called Senior Player (he was my draught-play mate). In fact I do not know his real name but he completed last year.

I quite remember we bumped into this Senior Player man in one of my friends at Presby's room last year and this course mate was teasing the guy, (Senior Player or SM for short), that the filla indicates that they were harassing the girl and even raped her when the girl was on campus. (By the chick had vanished form campus). This SM man then narrated to us how he came into contact with the girl. He said the girl approached he (sic) one day and told him her roommate had gone to lectures and as such, she would like to keep her things with him so that after lectures, she would come for them. It took three days for the girl to come back again with more items, giving the same excuse. As it turned out to be, the girl told him that her roommates are now four and as such, she can't cope with the situation so she intends changing hall to Baptist. However, the girl was not consistent in most of her information so he decided to do away with her and he was sure that was why the girl was spreading such a false filla.

I quite remember we saw this chick only twice at any lecture area on all these occasions she was entering lecture rooms where nobody was there. Then just as the lecture ends, she will join the multitude as if she was part of the class. One interesting thing is that I found this girl almost always walking alone on a road where students even hardly pass. Later filla indicated that she was complaining about how people were talking about her (as to how she got to know of that "dee", only God Knows).

Long after matriculation when admission ceased, my roommate and I met this girl coming out of our main Library with a pen in hand. In a chat, she said she was offered "Computer Science" and she went and did some research work in Mathematics because it was giving her tough times. After this meeting, my roommate began to entertain some surprise because as far as he was aware this girl was registered among the Arts Students when she was sacked at PSXY. So here in comes my agitations (sic).

Kwesi, you will hear from me again. I need to see you in person and talk over bottles.

Kwesi, have my condolence for your pop's death, and keep on tormenting those in office for them to live upright lives.

(THE GHANAIAN CHRONICLE, 15-18 ${ }^{\mathrm{TH}}$ September 1994). 


\section{Notes}

Note 1 . The readership of the paper in question can be said to have a relatively high level of education and be

Note 2. Smaller vehicles/buses used for passenger transport.

Note 3. High-life is a Ghanaian art form: song and dance.

Note 4. Ashokabula: 'a' (wa): pidgin $3^{\text {rd }}$ person personal pronoun: male/female; 'shoka': from the English verb shock; 'bula': Hausa word for penis.

Note 5. Told me / whispered to me (student slang)

Note 6. Paddy is GhaE (Ghanaian English) 'buddy’ - probably from pal+buddy.

Note 7. Taboo word for male organ - of Hausa origin.

Note 8. Have intercourse with her (student slang)

Note 9. Though this use of 'girl' is not as common in Ghana as in, for instance, Southern Africa.

Note 10. Seeking admission (to the university).

Note 11. Teaching Assistant

Note 12. deceived

Note 13. Story

Note 14. C.S. contrastive from Akan.

Note 15. made up.

Note 16. 'Senior man' / 'Senior player' - student slang.

Note 17. Mental patients are often considered dangerous...,

Note 18. Story / gossip

Note 19. A term used to indicate language that falls short of the target.

Note 20. Hausa is originally a Nigerian language. It is a West African lingua franca. Some profane Hausa items are found in GhaE; these entered the language when most Hausa speakers were itinerant male workers in the country. Today Hausa, in a pidginised form that is creolising itself, is widely spoken in Ghana and it also functions as an L1. 